\title{
Gerenciamento de resíduos sólidos perigosos: uma avaliação da gestão ambiental da borra oleosa na Petrobras/Lubnor
}

\author{
Monica Cavalcanti Sá Abreu \\ Departamento de Administração da Faculdade de Economia, Administração, Atuárias e Contabilidade - UFC \\ mabreu@ufc.br

\section{Liciane Carneiro Magalhães} \\ Universidade Federal do Ceará - UFC \\ licianecarneiro@yahoo.com.br \\ Carlos José Holanda Gurgel \\ Engenheiro de Processamento de Petróleo Sênior - PETROBRAS \\ cjgurgel@petrobras.com.br
}

\section{RESUMO}

O presente trabalho apresentao Plano de Gerenciamento de Resíduos Sólidos (PGRS) desenvolvido na LUBNOR, uma refinaria da PETROBRAS, localizada em Fortaleza/Ceará. Os resíduos sólidos perigosos foram caracterizados, quantificados e tiveram seus riscos ambientais identificados, tomando por base a legislação vigente. O resíduo borra oleosa foi identificado com o principal resíduos a ser gerenciado, em virtude do risco ambiental, da sua geração em todas as fases do processo produtivo e da quantidade armazenada na Central de Resíduos. O trabalho apresenta os procedimentos de segregação, armazenamento e disposição final da borra oleosa, mostrando os custos ambientais decorrentes de cada uma destas etapas. Paralelamente, os registros de tratamento de anomalias foram avaliados a fim de identificar as causas de derramamentos de produtos cujos procedimentos de limpeza geravam a borra oleosa. A avaliação da gestão ambiental da borra oleosa envolveu o rastreamento, a quantificação e a identificação das causas de geração deste resíduo. O trabalho apresenta medidas de bloqueio e mitigadoras do impacto ambiental da borra oleosa com as recomendações para a melhoria do PGRS.

Palavras-chave: Plano de Gerenciamento de Resíduos Sólidos, Resíduos perigosos, Borra oleosa, Gestão Ambiental, Custos ambientais.

\begin{abstract}
This paper presents the Solid Waste Management Plan developed at PETROBRAS/LUBNOR, a refinery located in Fortaleza/Ceara-Brazil. The methodology was adopted using a systematic collection of data from audit reports review and interviews with workers and managers. As a result of this assessment, productive activities/processes and solid wastes were identified. These solid wastes were characterized through legislation and environmental risks were identified. Also, the operational procedures were established. The results demonstrate that the main environmental risk involves oil sludge waste and its final destination. Furthermore, we identified the main reason of oil sludge generation and developed procedures based on pollution prevent guidelines. Environmental legislation, economics, environmental, health and operational security were considered in order to minimize the impacts caused by oil sludge waste.
\end{abstract}

Keywords: Solid Waste Management Plan, Oily sludge, Hazardous waste, Environmental management, Environmental cost.

\section{Introdução}

A conscientização da população em relação ao risco dos resíduos gera o aparecimento da chamada síndrome do NIMBY, que significa "not in mybackyard", isto é, "não no meu quintal". Também por temor do desconhecido e por motivos estéticos e comerciais, as comunidades passaram a rejeitar a instalação de aterros nas suas proximidades, mesmo que de forma temporária (VALLE, 2000). 
As inovações científicas e tecnológicas têm levado a sociedade a conhecer e a refletir sobre os impactos ambientais associados ao desenvolvimento econômico. Neste sentido, as empresas de petróleo e gás passaram a sentir a mudança de atitude dos stakeholders, por meio do aumento das exigências relacionadas com o desempenho ambiental empresarial. A questão ambiental está cada vez mais presente no ciclo de debates sobre competividade, o que pressiona a indústria de petróleo e gás a direcionarem seus investimentos no aprimoramento de sistemas de gestão e no desenvolvimento de produtos e processos.

De acordo com Soares (2000), para fazer frente a este cenário as empresas internacionais de petróleo e gás desenvolvem as seguintes estratégias: aumentar a eficiência operacional; intensificar o uso de matérias-primas mais econômicas; reduzir custos logísticos; modernizar as instalações e sistemas de segurança industrial; expandir a atuação em mercados de alto potencial e promover investimentos nas atividades de pesquisa.

Observa-se, no entanto, a necessidade de desenvolver ferramentas de gestão, que permitam mitigar os impactos ambientais das atividades da indústria de petróleo e gás. Pires et al. (2003) aponta que os resíduos sólidos gerados nas indústrias petroquímicas representam um grande desafio para as áreas responsáveis pelas pesquisas em planejamento e operação do sistema de destino final de resíduos sólidos. Rojas et al. (2008) afirma que crescem as iniciativas de programas de preservação e gerenciamento ambiental capazes de minimizar o volume e a toxicidade dos resíduos industriais.

O trabalho apresenta, portanto, o plano de gerenciamento de resíduos sólidos da refinaria LUBNOR, uma unidade de negócios do sistema PETROBRAS. Dentre os resíduos perigosos gerados na refinaria, destaca-se a necessidade de minimizar o impacto ambiental da borra oleosa. As borras oleosas são emulsões basicamente compostas por óleo, água e sólidos grosseiros. Sua composição é extremamente variável, dificultando o seu reaproveitamento, e lhe confere significativa recalcitrância. Este resíduo é classificado, segundo a NBR 10004 (2004), como Perigoso - Classe I em função de suas características de inflamabilidade, corrosividade, reatividade, toxicidade e patogenicidade.

Em 2003, a Superintendência Estadual do Meio Ambiente do Estado do Ceará (SEMACE) proibiu o envio da borra oleosa para a queima em empresas produtoras de cerâmicas. Paralelamente, a PETROBRAS, através do Programa de Excelência em Gestão Ambiental e Segurança Operacional (PEGASO) iniciou um processo de auditoria nos aterros classe I, e recomendou que suas refinarias não mais destinassem a borra oleosa para aterros industriais. Impossibilitada de dar um destino final responsável a borra oleosa, durante o período da pesquisa (2003-2005), a LUBNOR armazenou em sua Central de Resíduos mais de 300 toneladas de borra oleosa. Este montante representou um significativo risco ao meio ambiente, a saúde e a segurança operacional exigindo uma melhor gestão ambiental da borra oleosa.

Os resultados da pesquisa refletem o esforço da PETROBRAS/LUBNOR para a implantação e melhoria do programa de gerenciamento de resíduos (PGRS) no âmbito do seu Sistema de Gestão Integrado da Qualidade, Meio Ambiente, Segurança e Saúde. O PGRS considera a legislação ambiental vigente e os aspectos econômicos, ambientais e de segurança operacional. O trabalho contribui com a avaliação das oportunidades de melhorias operacionais na gestão ambiental da borra oleosa, tomando por base os princípios da prevenção da poluição.

\section{Resíduos Sólidos: Conceitos, Tecnologias de Tratamento e Prevenção da Poluição}

A Associação Brasileira de Normas Técnicas (ABNT), através da NBR 10004 (2004), define resíduos sólidos como sendo "resíduos nos estados sólido e semisólido, resultantes de atividades de origem: industrial, doméstica, hospitalar, comercial, agrícola, de serviços e de varrição. Ficam incluídos nesta definição os lodos provenientes de sistemas de tratamento de efluentes líquidos, de fossas assépticas, de estação de tratamento de água, aqueles gerados em equipamentos e instalações de controle de poluição, bem como determinados resíduos líquidos cujas particularidades tornem inviável seu lançamento na rede pública de esgotos ou corpos de água, ou exijam para isto solução técnica e economicamente inviáveis em face à melhor tecnologia disponível”.

A NBR 10004 (2004) classifica os resíduos quanto aos seus riscos potenciais ao meio ambiente e à saúde pública. Essa classificação está dividida em resíduos classe I e classe II.Os resíduos classe I são resíduos sólidos ou mistura de resíduos sólidos que, em função de suas características de inflamabilidade, corrosividade, reatividade, toxicidade e patogenicidade, podem apresentar risco à saúde pública.

Os resíduos de classe II não são perigosos e apresentamse divididos em classe IIA e II B. De acordo com a NBR10004 (2004), os resíduos classe II-B são denominados de inertes, pois quando são submetidos a um contato estático ou dinâmico com água destilada ou deionizada, à temperatura ambiente, não tem nenhum de seus constituintes solubilizados a concentrações superiores aos padrões da potabilidade de água. Os resíduos classe IIA são não inertes e não se enquadram 
nas classificações de resíduos classe I - perigosos ou de resíduos classe II B - inertes. Podem ainda apresentarem propriedades tais como: combustibilidade, biodegrabilidade ou solubilidade em água.

Dessa forma, a classificação de um resíduo é de fundamental importância na definição dos custos do programa de gerenciamento de resíduo. Este programa deve assegurar que todos os resíduos sejam gerenciados de forma apropriada e segura, desde a geração até a disposição final ("do berço ou túmulo"). As etapas envolvem a geração, caracterização, manuseio, acondicionamento, coleta, transporte, reuso/reciclagem, tratamento e disposição final do resíduo sólido. (CETESB, 1993).

Atualmente estão disponíveis tecnologias, normas e legislações para operacionalização da metodologia e ferramentas para os gerenciamentos dos resíduos sólidos industriais. São elas: auditoria de redução de resíduos, inventário de resíduos industriais, bolsa de resíduos, produção ambientalmente consciente, técnica de prevenção à poluição, técnica de minimização de resíduos, sistema de gestão ambiental, análise do ciclo de vida de um produto e o desenvolvimento de indicadores ambientais.

A auditoria de redução de resíduos ajuda o gerenciamento dos diferentes tipos de resíduos, contendo em si pergunta relacionada com o local de geração de resíduo, a quantidade e a redução potencial. Durante a auditoria são questionados: Onde o resíduo é gerado? Quando o resíduo foi gerado? Qual a quantidade de resíduo gerado? Qual a redução potencial do resíduo? Como pode ser reduzida a quantidade de resíduo? Qual a melhor alternativa para o gerenciamento do resíduo remanescente?

Segundo Brasil (2002), inventário de resíduos industriais é o conjunto de informações sobre a geração, caracterização, armazenamento, transporte, tratamento, reutilização, reciclagem, recuperação e disposição final dos resíduos sólidos gerados pelas indústrias do país. A bolsa de resíduos estimula a reciclagem, que por sua vez reduz custos, e consequentemente desperdícios, até mesmo criando receita, pois o gerador deixa de gastar com a coleta, transporte, tratamento e disposição, para ganhar com a venda.

Para Sarkis e Rasheed (1995), produção ambientalmente consciente desenvolve produtos que sejam reciclados e reutilizados, tendo como benefícios, indústrias mais limpas e seguras com menores custos na disposição dos resíduos e de segurança do trabalho. Segundo CNTL (2002), a produção mais limpa $(\mathrm{P}+\mathrm{L})$ é uma técnica da prevenção à poluiçãocom a aplicação contínua de uma estratégia econômica, ambiental e tecnológica integrada aos processos e produtos. A prevenção da poluição possui o objetivo de aumentar a eficiência no uso das matérias-primas, água e energia através da não geração, minimização ou reciclagem de resíduos gerados em todos os setores produtivos. A técnica de minimização de resíduos aumenta a ecoeficiência dos processos produtivos. São divididas em: gerenciamento de materiais e estoque, modificações no processo de produção, redução do volume e recuperação.

Os processos de tratamento de resíduos se dividem em físicos, químicos, biológicos e térmicos. Os tratamentos físicos são métodos de separação de fases. Os tratamentos químicos são transformações químicas, gerando reações para recuperar constituintes específicos. Os tratamentos biológicos objetivam degradação de compostos orgânicos pela ação de microorganismos. E por fim os tratamentos térmicos visam a destruição de compostos, redução do volume ou recuperação de energia. Dessa forma, é extremamente necessário conhecer as características do resíduo para que o método mais adequado seja escolhido. Essas características são: origem; estado físico (sólido, líquido ou pastoso); constituintes e suas faixas de concentração; classificação segundo a NBR 10004 (2004) e os custos operacionais.

A disposição final para resíduos industriais perigosos é permitida em aterros classe I, denominados de aterro de resíduos industriais perigosos (ARIP). A NBR 8418 (1983) define ARIP como uma "técnica de disposição de resíduos industriais perigosos no solo, sem causar danos ou riscos à saúde pública e à sua segurança, minimizando os impactos ambientais. Este método utiliza princípios de engenharia para confinar os resíduos industriais perigosos à menor área possível e reduzi-los ao menor volume permissível, cobrindo-os com uma camada de terra na conclusão de cada jornada de trabalho ou a intervalos menores se for necessário".

De acordo com o CNTL (2001), as decisões técnicas e econômicas tomadas em relação aos resíduos sólidos perigosos estocados nas indústrias, baseiam-se em informações preliminares, que levam em consideração, principalmente, os aspectos de saúde ocupacional, qualidade ambiental, exequiibilidade da medida e custos envolvidos.

\subsection{Tecnologias Existentes para o Tratamento da Borra Oleosa}

A disposição responsável do resíduo borra oleosa é um aspecto ambiental significativo para a indústria de petróleo e gás. Segundo Xu et al. (2009), uma considerável quantidade de borra oleosa é gerada durante os processos de exploração, produção de óleo cru, transporte, estocagem e refino de petróleo. Van Oudenhoven et al. (1995) estimam que para cada 500 ton de oleo cru processado seja gerada 1 tonde borra 
oleosa. Roldán-Carrillo et al. (2012) esclarecem que a borra oleosa é uma complexa mistura com distintas propriedades físico-químicas com uma ampla variedade de níveis de toxidez.

De acordo com Zhang et al. (2012), a borra oleosa é uma emulsão composta de água-óleo, com cerca de $30-50 \%$ de óleo, 30-50\% de água e 10-12\% de sólidos. A estrutura molecular do contaminante determina suas propriedades químicas e sua biodegradabilidade. Castorena-Cortés et al. (2009) afirmam este cenário é muito mais complicado em sistemas contaminados com borra oleosa, solo e sedimentos, em virtude da existência de diversos hidrocarbonetos em elevadas e diferentes concentrações. Como resultado estes sistemas são mais tóxicos e os tratamentos são consequentemente mais complexos.

Um dos sistemas de tratamento da borra oleosa de menor custo é o tratamento biológico denominado de landfarming. Segundo McCarthy et al. (2004), este tratamento envolve a adição de nutrientes e água, e o periódico cultivo para misturar e arear o solo. É um sistema que utiliza propriedades físicas e químicas do solo e da atividade microbiana neste meio para degradação da borra oleosa. É uma alternativa atrativa para lugares remotos, pois é um procedimento tecnicamente simples e relativamente barato. Segundo Trindade et al. (2005), a biorremediação acelera a ocorrência natural da biodegradação sobre boas condições como suprimento de oxigênio, temperatura, $\mathrm{pH}$, a presença ou a adição de população microbiana conveniente e nutrientes, conteúdo de água e mistura.

Embora os custos dos tratamentos biológicos (landfarming) sejam baixos, Al-Futaisi et al. (2007) argumenta que este tipo de tratamento exige uma grande quantidade de espaço físico, necessita de gerenciamento e controle, e que existe um risco de falha na redução dos níveis de contaminantes inorgânicos. Os autores sugerem outras técnicas para gerenciamento da borra oleosa, tais como solidificação e reuso em pavimento asfálticos. Outras técnicas envolvem reciclagem, incineração, reprocessamento com altas temperaturas e tratamentos químicos com solventes. Os resíduos de fundo de tanque e óleo cru contaminado podem ser utilizados como pavimentos asfálticos. Porém, do ponto de vista ambiental é necessário que sejam considerados os constituintes perigosos da borra oleosa, aplicação apropriada dos procedimentos operacionais e a proteção do meio ambiente.

A incineração é um tratamento térmico utilizado para eliminar o conteúdo orgânico do resíduo oleoso reduzindo-o as cinzas que podem ser dispostas no solo. Outro exemplo de tratamento térmico é o co-processamento que consiste em um processo de combustão da borra oleosa em fornos de indústrias de cimento.
Neste processo, o conteúdo orgânico da borra oleosa étransformado em cinzas e incorporado ao cimento produzido (TREZZA; SCIAN, 2004). As companhias de cimento estão introduzindo os resíduos industriais no co-processamento, combinando políticas ambientais com interesses empresariais.

A borra oleosa pode ser usada como um combustível alternativo nas companhias de cimento, porém existem problemas associados a este tratamento. Al-Futaisi et al. (2007) apontam o grande volume de efluentes gasosos que precisam ser adequadamente tratados, além das cinzas resultantes dos processos de incineração que podem conter metais pesados que devem ser dispostos com segurança.

Outro tratamento específico para a borra oleosa é o encapsulamento de contaminantes. Esta tecnologia de encapsulamento é considerada uma forma segura de tratamento para uma variedade de contaminantes, incluindo os resíduos oriundos da indústria de petróleo. Rojas et al. (2008) aplicou a técnica de encapsulamento em um solo contaminado com crescentes quantidades de borra oleosa, utilizando como agente encapsulante o cimento Portland CP-V ARI. Os resultados apontam que quanto maior a quantidade de borra oleosa ácida presente no solo encapsulado menor é a resistência a compressão simples e maior a perda de massa.

Karamalidis e Voudrias (2007) afirmam que os processos de estabilização/solidificação para a imobilização de constituintes de resíduos sólidos é amplamente utilizado principalmente para metais pesados. No entanto, resultados com a imobilização de borra oleosa com cimento não tem apresentado resultados satisfatórios. Os experimentos realizados mostram que os resíduos são confinados em cimento em uma matriz de macroencapsulamento. Porém, a ruptura da estrutura do cimento ocorre em virtude do aumento da lixiabilidade da maioria dos hidrocarbonetos.

Zhang et al. (2012) apontam que o tratamento de recuperação de óleo da borra que contenha acima de $10 \%$ de hidrocarbonetos de petróleo (PHC) pode ser economicamente viável. A recuperação de óleo pode reduzir significativamente os $\mathrm{PHC}$, tornando eficientes os processos convencionais tais como landfarming e provendo uma concentração não-tóxica para a atividade microbiana. Os autores testaram uma combinação de métodos que incluem tratamentos com ultrassom e congelamento/liquefação. Os resultados alcançados apontam no sentido do desenvolvimento de métodos ambientalmente corretos e economicamente viáveis para o tratamento da borra oleosa. 


\section{Metodologia}

A pesquisa caracteriza-se como um estudo de caso de caráter exploratório e descritivo, adotando uma abordagem quantitativa. O estudo foi desenvolvido na LUBNOR, uma unidade de refino da PETROBRAS instalada em Fortaleza/Ceará que possui uma produção de $1.100 \mathrm{~m}^{3} /$ dia. A refinaria adota a segmentação de mercado e o agrupamento de clientes em função da demanda dos diversos produtos comercializados. Atua como terminal de importação e de cabotagem para o abastecimento de combustíveis para o mercado local. Suas instalações industriais foram planejadas e têm sido operadas com a orientação de atender à demanda regional de combustíveis, derivados e asfaltos e a demanda nacional de lubrificantes naftênicos.

O primeiro passo deste estudo foi o mapeamento dos processos de produção de asfaltos, combustíveis, lubrificantes e derivados com a identificação dos resíduos gerados. O mapeamento do fluxo produtivo da PETROBRAS/LUBNOR ocorreu através da avaliação de fluxogramas de entradas e saídas, com o objetivo de identificar as entradas (matéria-prima) e saídas (produtos ou resíduos) de cada etapa do processo produtivo. Após essa identificação das entradas e saídas, foi construída uma matriz que relaciona os processos produtivos e seus devidos resíduos. Com isso pôde-se ter uma visão mais ampla de todo o sistema produtivo da PETROBRAS/ LUBNOR, suas atividades auxiliares e os resíduos gerados. A elaboração do plano de gerenciamento de resíduos sólidos (PGRS) foi a etapa seguinte.

O trabalho apresenta, portanto, a descrição das fases de elaboração e de operacionalização do PGRS. Os aspectos e impactos ambientais dos resíduos perigosos gerados na refinaria foram avaliados e a "geração", "armazenamento" e "destino final" da borra oleosa foram identificados como aspectos ambientais significativos. Foram adotados os critérios "volume de resíduo armazenado" na Central de Resíduos eos "riscos operacionais, ambientais e de segurança e saúde ocupacional" para a seleção da borra oleosa como principal resíduo a ser gerenciado. Adicionalmente, durante o período da pesquisa, a SEMACE e a PETROBRAS proibiram o envio da borra oleosa para a queima em empresas de fabricação de cerâmicas no estado do Ceará e para aterros industriais de qualquer classe na região Nordeste, agravando significativamente o problema do destino final da borra oleosa.

Os processos que envolviam a geração, armazenamento e destino final da borra oleosa foram estudados detalhadamente e as informações coletadas foram organizadas em gráficos quantitativos e comparativos que evidenciassem as causas mais relevantes do problema. Os dados da pesquisa foram coletados entre 2003 e 2005, a partir da análise dos relatórios de auditorias interna (RTA - registro e tratamento de anomalias), procedimentos operacionais, entrevistas com a força de trabalho e observação participante.

Também foram levantados os custos das opções de destinação final responsável da borra oleosa, identificando o destino mais adequado com base em critérios econômicos. O trabalho apresenta ainda, recomendações para as melhorias do plano de gerenciamento de resíduos perigosos da PETROBRAS/LUBNOR, e em especial trata do bloqueio aos aspectos e impactos ambientais causados pela borra oleosa.

\section{Resultados}

\subsection{Levantamento dos Resíduos Gerados nos Processos Produtivos da Refinaria}

Os processos e os resíduos foram identificados gerando uma matriz que permite relacionar cada resíduo ao seu processo gerador. Esta matriz foi elaborada, a partir de visitas técnicas a área industrial, e de entrevistas com os empregados da PETROBRAS/LUBNOR e das empresas contratadas, nas diversas áreas/atividades industriais, conforme apresentada no Quadro 1.

A refinaria tem como processos produtivos uma Unidade de Destilação à Vácuo (UVAC), uma Unidade de Lubrificantes Naftênicos (ULUB) e uma Unidade de Processamento de Gás Natural (UPGN). A UVAC é responsável pela maior parcela do faturamento global da empresa. Disponibiliza, principalmente, asfaltos e combustível ao mercado local além de fornecer insumos à Unidade de Lubrificantes Naftênicos (ULUB) para processamento e geração de lubrificantes. 


\begin{tabular}{|c|c|c|c|c|c|c|c|c|c|c|c|c|c|c|c|c|}
\hline $\begin{array}{l}\text { Processos } \\
\text { Resíduos } \downarrow\end{array}$ & 帒 & 号 & $\begin{array}{l}\text { Z } \\
\vdots \\
\vdots\end{array}$ & 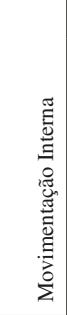 & 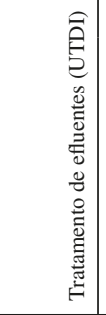 & 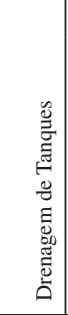 & 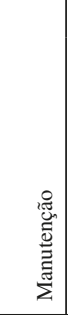 & 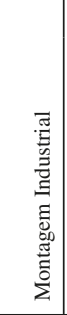 & 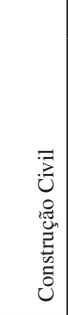 & 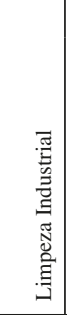 & 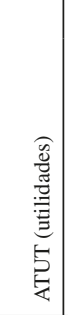 & 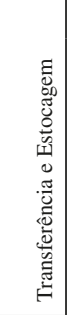 & 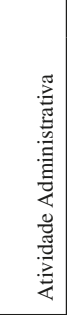 & 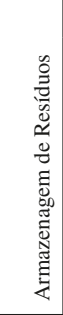 & 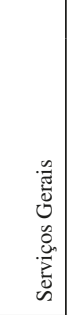 & 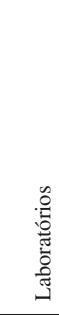 \\
\hline Areia Oleosa & & & & $\mathrm{X}$ & & & & & & $\mathrm{X}$ & & & & $\mathrm{X}$ & & \\
\hline Baterias usadas & & & & & & & $\mathrm{x}$ & & & & $\mathrm{X}$ & & $\mathrm{X}$ & $\mathrm{X}$ & $\mathrm{X}$ & \\
\hline Borra asfáltica com solos e britas & & & & $\mathrm{X}$ & & & & & & $\mathrm{X}$ & & & & $\mathrm{X}$ & & \\
\hline Borra asfáltica pura & & & & $\mathrm{X}$ & & & & & & & & & & $\mathrm{X}$ & & \\
\hline Borra de Tanques & & & & & & & $\mathrm{x}$ & & & & & & & $\mathrm{x}$ & & \\
\hline Borra da UTDI & & & & & $\mathrm{x}$ & & $\mathrm{x}$ & & & & & & & $\mathrm{x}$ & & \\
\hline Cartuchos de impressora & & & & & & & & & & & & & $\mathrm{x}$ & $\mathrm{x}$ & & \\
\hline Catalisador & & $\mathrm{x}$ & & & & & $\mathrm{x}$ & & & & & & & $\mathrm{x}$ & & \\
\hline Efluentes oleosos & $\mathrm{X}$ & $\mathrm{X}$ & $\mathrm{X}$ & & & $\mathrm{X}$ & $\mathrm{X}$ & & & & $\mathrm{X}$ & $\mathrm{X}$ & & & & $\mathrm{X}$ \\
\hline Entulho & & & & & & & $\mathrm{X}$ & $\mathrm{X}$ & $\mathrm{X}$ & & & & $\mathrm{X}$ & & $\mathrm{X}$ & \\
\hline Graxa usada & & & & & & & $\mathrm{x}$ & $\mathrm{x}$ & & $\mathrm{x}$ & $\mathrm{x}$ & $\mathrm{x}$ & $\mathrm{X}$ & $\mathrm{x}$ & $\mathrm{x}$ & $\mathrm{x}$ \\
\hline $\begin{array}{l}\text { Lâmpadas fluorescentes, a vapor de } \\
\text { mercúrio e outras }\end{array}$ & $\mathrm{X}$ & $\mathrm{X}$ & $\mathrm{X}$ & & $\mathrm{X}$ & & $\mathrm{X}$ & & $\mathrm{x}$ & & & & & & & \\
\hline $\begin{array}{l}\text { Latas com restos de tinta e vernizes e } \\
\text { sprays }\end{array}$ & & & & & & & $\mathrm{X}$ & $\mathrm{X}$ & $\mathrm{X}$ & & & & & $\mathrm{X}$ & $\mathrm{X}$ & \\
\hline Lixo hospitalar em geral & & & & & & & & & & & & & $\mathrm{X}$ & $\mathrm{X}$ & & \\
\hline Lixo oleoso & & & & & & & $\mathrm{X}$ & & & $\mathrm{X}$ & & $\mathrm{X}$ & & $\mathrm{X}$ & & $\mathrm{X}$ \\
\hline Lixo orgânico & & & & & & & & & & $\mathrm{X}$ & & & $\mathrm{x}$ & & $\mathrm{X}$ & \\
\hline Óleos lubrificantes & & & & & & & $\mathrm{x}$ & & & & & & & $\mathrm{x}$ & & \\
\hline Pigs usados (sujos de óleo) & & & $\mathrm{X}$ & & & & & & & & & & & $\mathrm{X}$ & & \\
\hline Poliuretano (isolamento) & & & $\mathrm{X}$ & & & & & & & & & & & $\mathrm{X}$ & & \\
\hline $\begin{array}{l}\text { Resíduos laboratoriais e produtos ven- } \\
\text { cidos }\end{array}$ & & & & & & & & & & & & & & $\mathrm{X}$ & & $\mathrm{X}$ \\
\hline Resíduos de varrição & $\mathrm{X}$ & $\mathrm{X}$ & $\mathrm{X}$ & & $\mathrm{X}$ & $\mathrm{X}$ & $\mathrm{X}$ & $\mathrm{X}$ & $\mathrm{X}$ & $\mathrm{X}$ & $\mathrm{X}$ & $\mathrm{X}$ & $\mathrm{X}$ & $\mathrm{X}$ & $\mathrm{X}$ & $\mathrm{X}$ \\
\hline $\begin{array}{l}\text { Recipientes contaminados por produtos } \\
\text { químicos }\end{array}$ & & & & & & & $\mathrm{x}$ & $\mathrm{X}$ & & & & & & $\mathrm{x}$ & $\mathrm{x}$ & $\mathrm{X}$ \\
\hline Resíduo oleoso da UTDI & & & & & $\mathrm{X}$ & & & & & & & & & & & \\
\hline Silicato & $\mathrm{X}$ & $\mathrm{X}$ & $\mathrm{X}$ & & & & $\mathrm{X}$ & $\mathrm{X}$ & & & $\mathrm{X}$ & $\mathrm{X}$ & & $\mathrm{X}$ & & \\
\hline Sucata ferrosa e não ferrosa & $\mathrm{X}$ & $\mathrm{X}$ & $\mathrm{X}$ & $\mathrm{X}$ & $\mathrm{X}$ & & $\mathrm{X}$ & $\mathrm{X}$ & & $\mathrm{X}$ & $\mathrm{X}$ & & & $\mathrm{X}$ & $\mathrm{X}$ & \\
\hline Trapos sujos de óleo & $\mathrm{X}$ & $\mathrm{X}$ & $\mathrm{X}$ & $\mathrm{X}$ & $\mathrm{x}$ & $\mathrm{X}$ & $\mathrm{X}$ & $\mathrm{X}$ & & $\mathrm{X}$ & $\mathrm{X}$ & $\mathrm{X}$ & & $\mathrm{X}$ & $\mathrm{X}$ & $\mathrm{X}$ \\
\hline Tambores vazios & $\mathrm{x}$ & $\mathrm{x}$ & $\mathrm{x}$ & & $\mathrm{X}$ & & $\mathrm{x}$ & $\mathrm{x}$ & & & $\mathrm{x}$ & $\mathrm{x}$ & & $\mathrm{x}$ & $\mathrm{X}$ & \\
\hline Transformadores e/ou capacitores & & & & & & & $\mathrm{x}$ & & & & $\mathrm{x}$ & & & $\mathrm{X}$ & & \\
\hline
\end{tabular}

Quadro 1. Matriz contendo a relação dos Processos Produtivos com os Resíduos Gerados

Fonte: dados coletados na pesquisa de campo

A planta da UVAC tem capacidade de processar 1.100 $\mathrm{m}^{3} /$ dia de petróleo. A matéria-prima (petróleo) processada na UVAC vem de campos de Exploração e Produção (E\&P) da Petrobras, Fazenda Alegra (FAL) e Fazenda Belém (FZB). A ULUB é composta pela Unidade de Geração de Hidrogênio (UGH) e a unidade de Hidrotratamento (HDT). A UGH tem a capacidade de produzir, diariamente até $35.000 \mathrm{~m}^{3}$ de hidrogênio com 99,9\% de pureza. Utiliza como matéria-prima o gás residual de alta pressão fornecida pela Unidade de Processamento de Gás Natural (UPGN).
Utilizando como matéria-prima os gasóleos produzidos na UVAC, a Unidade de Hidrotratamento (HDT) tem capacidade nominal de produzir até $58.200 \mathrm{~m}^{3} /$ ano de lubrificantesnaftênicos. Dependendo da fração de gasóleos processado são produzidos três tipos de lubrificantes: NH-10, NH-20, NH-140 e óleo para transformadores (ISOVOLT). A unidade pode ainda ser utilizada para a produção de diesel metropolitano.A UPGN processa até $350.000 \mathrm{~m}^{3}$ de gás natural oriundo dos campos da plataforma continental do Ceará, produzindo gás residual (combustível) para as indústrias 
do Distrito Industrial de Fortaleza, gás liquefeito de petróleo (GLP) e gasolina natural (C5+).

As borras oleosas são geradas em maior quantidade na refinaria durante todas as etapas de produção, transporte e refino de petróleo (sinalizadas em cinza no Quadro 01). Durante o mapeamento de processos, percebeu-se que a geração de borra oleosa é resultado dos processos que operacionalizam o sistema produtivo, ou seja, dos processos que gerenciam o armazenamento e a distribuição de matéria-prima e produto acabado, a manutenção de equipamentos e tanques, a limpeza de tubo, vias e canaletas de águas oleosas.

\subsection{Operacionalização do Plano de Gerenciamento de Resíduos Sólidos (PGRS)}

A operacionalização do PGRS ocorre em condições normais e anormais de operação ou em situações de emergência. O PGRS envolve o registro, classificação, manuseio, armazenamento temporário e definitivo, permissão para movimentação e transporte, bem como, para segregação, remoção e disposição final de todo resíduo semi-sólido, sólido, oleoso ou não. Os resíduos sólidos são encaminhados para uma central de resíduos onde são segregados e armazenados temporariamente, até a destinação final, que pode ocorrer em aterro sanitário, reciclagem ou incineração, atendendo a legislação vigente.

Os resíduos são classificados de acordo com a norma NBR 10004 (2004). Os resíduos são movimentados dentro da refinaria mediante uma ficha de movimentação interna de resíduos. Quanto às precauções de segurança e saúde do trabalho, emergências e proteção ao meio ambiente, os resíduos perigosos são analisados antes de sua disposição final e gerenciados quanto aos seus riscos físicos, químicos, biológicos e seu potencial de gerar acidentes, doenças, emergências e impactos ambientais adversos.

Os resíduos coletados nas diversas áreas da PETROBRAS/LUBNOR são encaminhados para a Central de Resíduos para que sejam segregados, pesados, embalados, e encaminhados para a disposição temporária ou disposição final. São acondicionados em embalagens adequadas de acordo com o estado físico e demais características de cada um. Os recipientes para coleta recebem os rótulos de identificação do resíduo e os rótulos de risco, quando se tratar de resíduos classe I, como no caso da borra oleosa, deve ser obedecida a NBR 7500 (2003).

Os documentos, tais como: licenças, manifestos, fichas de emergência, roteiros de viagem, planos de emergência são providenciados ou obtidos pela empresa contratada para operacionalizar o PGRS. A carga transportada para a destinação final é devidamente licenciada, controlada, identificada e acompanhada da documentação, conforme legislação pertinente. Antes de sair para a destinação final, a carga é inspecionada, e é preenchido um checklist de avaliação e emitido o manifesto de transporte de resíduo.

O resíduo somente é carregado na PETROBRAS/ LUBNOR para e envio ao destino final mediante a assinatura do manifesto de transporte de resíduo. A empresa responsável pela destinação final - destruição, reciclagem ou tratamento - emite o certificado de destinação final e o encaminha à PETROBRAS/LUBNOR.

Após o fechamento do mês, preenche-se uma planilha de movimentação e disposição de resíduos para a supervisão da PETROBRAS/LUBNOR. Quando houver autorização da Gerência Geral para o recebimento de resíduos de outros órgãos da PETROBRAS ou de entidade externa, deverá ser solicitada a licença ou autorização da Superintendência Estadual de Meio Ambiente (SEMACE) para transporte do resíduo e para recepção do resíduo no local de destino final. No caso de destinação final fora dos limites do Estado do Ceará, são atendidas as exigências dos órgãos ambientais dos estados envolvidos.

Caso um novo resíduo não tenha sido inicialmente cadastrado no PGRS deve ser identificado na fase de análise de risco de uma nova atividade/tarefa para que seja estabelecida preventivamente a forma correta de tratamento e disposição. A classe do novo resíduo deve ser definida utilizando-se a sequência do fluxograma para classificação de resíduos, conforme norma NBR 10004 (2004). Após a identificação da classe de risco do resíduo, é preenchida a ficha de coleta de dados do resíduo - CDR, e em seguida, elaborado o procedimento/padrão seguindo o modelo dos padrões dos demais resíduos.

\subsection{Análise dos Custos com a Geração, o Armazenamento e a Disposição Final da Borra Oleosa}

Segundo a Fédérationdes Experts Comptables Européens - FEE (1999) os custos ambientais compreendem "os custos das medidas tomadas ou requeridas para gerenciar os impactos ambientais das atividades de uma empresa e para atender aos seus objetivos ambientais". Os custos com a gestão ambiental da borra oleosa são de difícil mensuração e segregação, em função da distribuição destes itens de custeio entre os diversos setores produtivos da refinaria e da natureza predominantemente fixa destes custos. O Quadro 2 relaciona alguns itens de custeio na geração da borra oleosa e no armazenagem na Central de Resíduos, com indicadores adotados e os valores unitários para o cálculo dos custos ambientais. 


\begin{tabular}{|c|c|c|c|}
\hline $\begin{array}{c}\text { CUSTOS } \\
\text { AMBIENTAIS }\end{array}$ & ITENS DE CUSTEIO & INDICADORES & CUSTO (R\$) \\
\hline \multirow{4}{*}{ Custo da Geração } & \multirow{2}{*}{$\begin{array}{l}\text { Limpeza do local onde gerou o Resíduo } \\
\text { borra oleosa }\end{array}$} & - Custo da MO (homem/hora) & 7,39 \\
\hline & & - Tambores de 200 litros & $17,90 / \mathrm{UM}$ \\
\hline & Transporte do resíduo até a Central & - Aluguel da empilhadeira & $30,00 /$ hora \\
\hline & $\begin{array}{l}\text { Engenheiro para gerenciar o tratamento } \\
\text { e destinação adequada do resíduo borra } \\
\text { oleosa }\end{array}$ & - Over Head & $2,7 \%$ \\
\hline \multirow{4}{*}{ Custo da Armazenagem } & Investimento & $\begin{array}{l}\text { - Custo da construção do local de } \\
\text { armazenagem de resíduos }\end{array}$ & $230.000,00$ \\
\hline & \multirow[t]{2}{*}{ Manutenção da Central de Resíduos } & $\begin{array}{l}\text { - M.O. (homem/hora) que adminis- } \\
\text { tra a central de resíduos }\end{array}$ & 17,04 \\
\hline & & - recurso energia & $8,40 /$ dia \\
\hline & Armazenamento do resíduo & -Pallets (1 para 4 tambores) & $10,00 / \mathrm{UM}$ \\
\hline
\end{tabular}

Quadro 2: Itens de custo adotados para o controle da limpeza e armazenagem da borra oleosa. Fonte: Dados coletados na pesquisa de campo

Existe uma dificuldade de alocação dos custos com limpeza, transporte, "over head" do engenheiro ou mesmo da equipe responsável pela atividade. Estes custos estão distribuídos nas atividades de Manutenção, Apoio Administrativo (conservação e limpeza da refinaria) e da própria atividade de meio ambiente (SMS), que realiza outras atividades além da gestão de resíduos. No custo de armazenamento é possível quantificar o investimento na construção da Central de Resíduos para armazenamento temporário dos resíduos, conforme definido no PGRS, porém, o custo de armazenagem do resíduo também é de difícil alocação.

No ano de 2003 foram armazenados 123,20 toneladas de borra oleosa na Central de Resíduos. No ano de 2004 foram armazenadas mais 110,64 toneladas e até outubro de 2005 estavam armazenadas mais 76,08 toneladas de borra oleosa. No período da pesquisa estavam, portanto, armazenadas 309,92 toneladas de borra oleosa na Central de Resíduos. A partir das planilhas de inspeção interna dos tanques de armazenamento de petróleo e derivados, verificou-se também uma geração média anual de 56 toneladas de resíduo borra de tanque por ano decorrente de atividades de manutenção. Considerando, a proibição da SEMACE e da PETROBRAS com relação à queima deste resíduo em empresas produtoras de cerâmicas percebe-se que o controle da geração e do armazenamento do resíduo era um dos aspectos ambientais mais significativos da refinaria.

A PETROBRAS/LUBNOR pesquisou alternativas para a disposição final da borra oleosa. Foram analisadas quatro opções: disposição em aterros de resíduos perigosos
(ARIP) na empresa CINAL (Alagoas), incineração no incinerador de resíduos oleosos (I.R.O) da CETREL (Bahia), incorporação no asfalto e co-processamento na fábrica de Cimento Poty (Sobral/CE).

Tomando como referência os itens de custo definidos por Abreu e Sousa (2005), o custo das alternativas para disposição de uma carga completa de borra oleosa, equivalente a $10 \mathrm{~m}^{3}$ envolve os seguintes cálculos:

- Distância de Fortaleza/CE a Cinal - Companhia Alagoas Industrial, instalada no distrito industrial de Marechal Deodoro, 18 km de Maceió/AL: 1060km.

- Distância de Fortaleza/CE a CETREL S.A. Instalada em Salvador/BA: 1520 km.

- Distância de Fortaleza/CE a Fábrica de Cimento Potyem Sobral/CE: $233 \mathrm{~km}$

O Quadro 3 mostra o custo de cada proposta para tratamento de uma carreta de $10 \mathrm{~m}^{3}$ de resíduo. Não foram apresentados os custos para a alternativa "Incorporação no Asfalto", apesar da provável viabilidade técnica e ambiental da incorporação da borra oleosa ao asfalto/ pavimento. As pesquisas e estudos quanto à viabilidade da aplicação de borra oleosa e solo contaminado com petróleo (SCP) em pavimentação ainda estão em andamento pelas Universidades (Rede Asfalto). Alguns resultados positivos e promissores foram alcançados, porém não ainda existe uma conclusão definitiva quanto à viabilidade dessa aplicação. 


\begin{tabular}{|l|l|l|l|}
\hline \multirow{2}{*}{ ITENS DE CUSTO } & \multicolumn{4}{|l|}{ SOLUÇÕES PROPOSTAS } \\
\cline { 2 - 4 } & $\begin{array}{l}\text { ARIP - CINAL } \\
\text { ALAGOAS }\end{array}$ & $\begin{array}{l}\text { I.R.O - CETREL } \\
\text { BAHIA }\end{array}$ & $\begin{array}{l}\text { CIMENTO POTY SO- } \\
\text { BRAL }\end{array}$ \\
\hline Preço por km & $\mathrm{R} \$ 2,62$ & $\mathrm{R} \$ 2,62$ & $\mathrm{R} \$ 3,00$ \\
\hline Frete & $\begin{array}{l}1060 \mathrm{~km} \times 2 \times \mathrm{R} \$ 2,62= \\
\mathrm{R} \$ 5.554,40\end{array}$ & $\begin{array}{l}1520 \mathrm{~km} \times 2 \times \mathrm{R} \$ 2,62= \\
\mathrm{R} \$ 7.964,80\end{array}$ & $\begin{array}{l}233 \mathrm{~km} \times \mathrm{R} \$ 3,00=\mathrm{R} \$ \\
699,00\end{array}$ \\
\hline Custo para dispor $\left.\mathbf{( m}^{\mathbf{3}}\right)$ & $\mathrm{R} \$ 400,00$ & $\mathrm{R} \$ 1.000,00$ & $\mathrm{R} \$ 300,00$ \\
\hline Disposição de $\mathbf{1 0 \mathbf { m } ^ { 3 }}$ & $\mathrm{R} \$ 4.000,00$ & $\mathrm{R} \$ 10.000,00$ & $\mathrm{R} \$ 3.000,00$ \\
\hline $\begin{array}{l}\text { Custo para uma carreta } \\
\left(\mathbf{1 0} \mathbf{~}^{\mathbf{3}}\right) \mathbf{\text { de borra oleosa }}\end{array}$ & $\mathrm{R} \$ 9.554,40$ & $\mathrm{R} \$ 17.964,80$ & $\mathrm{R} \$ 3.699,00$ \\
\hline
\end{tabular}

Quadro 3: Custo das soluções para disposição final em aterro perigoso, incineração e co-processamento para cada carreta $\left(10 \mathrm{~m}^{3}\right)$ de borra oleosa.

Fonte: dados coletados na pesquisa de campo

Uma avaliação levando em conta os parâmetros frete, distância percorrida e custo unitário da disposição final, observa-se que tanto a disposição em aterro de resíduos industriais perigosos (ARIP) como a incineração na Cetrel (BA) elevariam os custos de gerenciamento da borra oleosa. O co-processamento em cimenteiras apresenta-se como a solução economicamente viável adequando-se a realidade local e atendendo aos critérios técnicos e ambientais.

A escolha da opção co-processamento na fábrica de Cimento Potyem Sobralvem sendo adotada desde 2005 para destinação final da borra oleosa da PETROBRAS/LUBNOR. Segundo dados da gerência de SMS da PETROBRAS/LUBNOR, o custo anual com o co-processamento gira em torno de $\mathrm{R} \$ 115.000,00 /$ ano. A empresa contratada é responsável pela coleta, segregação, blendagem, transporte e destinação final dos resíduos sólidos perigosos (Classe I). Vale esclarecer que no caso de algum evento gerador de borra (vazamentos, derrames, manutenção) todos os custos com as etapas de coleta nas áreas, envasamento, limpeza do local, transporte e estocagem na Central de Resíduos são de responsabilidade da PETROBRAS/ LUBNOR (atividade de Limpeza e Conservação). A empresa contratada recebe os resíduos em questão já devidamente entamborados e identificados para só então dar sua destinação final.

No co-processamento, a borra oleosa é completamente destruída (queima total em forno de clinker em temperaturas acima de 1.800 graus centígrados), com monitoramento e controle das emissões e a incorporação das cinzas ao cimento, não gerando qualquer tipo de resíduo adicional. Também existe o interesse da própria indústria de fabricação de cimento, que ganha em energia com a queima de um resíduo de elevado poder calorífico. A opção do co-processamento é, portanto, um bom negócio para ambas as partes.

\subsection{Identificação dos Vazamentos e Derramamentos de Produtos nos Registros de Tratamento de Anomalias}

Diante dos resultados apresentados, percebe-se que o problema na geração, armazenamento temporário de borra oleosa e disposição final exigia uma ação coordenada entre os setores: produtivo, manutenção e transferência e estocagem da refinaria, a fim de prevenir a geração de borra oleosa em decorrência de falhas operacionais, de manutenção e/ou de transporte.

Para que fosse possível realizar um rastreamento desde a geração até o acondicionamento dos resíduos borra oleosa foram analisados os registros de tratamento de anomalias (RTAs), abrangendo o período de 2003 à outubro de 2005, além de entrevistas com empregados da PETROBRAS/LUBNOR e terceirizados. Os registros de tratamento de anomalias descrevem a ocorrência, as causas, o impacto ambiental causado e a quantidade de produto derramado. A análise das RTAs revelou que os vazamentos e derramamento de produtos era a principal ocorrência que gerava borra oleosa, conforme apresentado no Quadro 4.

Para calcular a quantidade de resíduo gerado após um derramamento, multiplica-se o valor da quantidade derramada por um fator (f), o qual depende do tipo de produto. Durante o período estudo, foram registrados 7.071 litros de produto derramado. É importante ressaltar que a quantidade derramada de produto em cada ocorrência é menor que a quantidade armazenada na Central de Resíduos, pois o solo dos tanques de contenção é removido junto com o resíduo.

A partir de entrevistas realizadas com os responsáveis pela limpeza da área industrial constatou-se que o volume de resíduos varia para cada produto. Para cada 50 litros de asfalto diluído de Cura Média (CM-30) e 
de Cura Rápida (CR-250) derramado é necessário um tambor de 200 litros para realizar a remoção completa do resíduo, o mesmo acontece com o Marine Fuels (MF180 e 380). Para cada 50 litros de Cimento Asfáltico de Petróleo (CAP 50/60) são necessários 3 tambores de 200 litros, em virtude do CAP ser mais viscoso e solidificar-se rapidamente quando derramado. Com o petróleo cru, para cada 50 litros derramado são necessários de 2 tambores de 200 litros.
Para o CM-30 e CR-250 e o MF180 e 380 o fator é 4, para o CAP 50/60 o fator é 12 e para o petróleo cru o fator é 8 . Observa-se uma diferença entre a quantidade anual de produto derramado transformada em resíduo registrada nas RTAs e a quantidade de borra oleosa registrada na planilha anual de acompanhamento. Esta diferença é decorrente da quantidade de borra de tanque proveniente da manutenção programada dos tanques.

\begin{tabular}{|c|c|c|c|c|c|c|c|c|}
\hline \multirow{3}{*}{$\begin{array}{c}\text { Tipo } \\
\text { Ocorrência }\end{array}$} & \multirow{3}{*}{\begin{tabular}{|c}
$\mathrm{N}^{\circ} \mathrm{de}$ \\
Ocorrências
\end{tabular}} & \multirow{2}{*}{\multicolumn{5}{|c|}{$\begin{array}{c}\text { Distribuição das Causas Prováveis por Ocorrência } \\
\text { Registrados (Litros) }\end{array}$}} & \multicolumn{2}{|c|}{$\begin{array}{l}\text { Quantidade do } \\
\text { Vazamento }\end{array}$} \\
\hline & & & & & & & \multirow{2}{*}{$\begin{array}{c}\begin{array}{c}\text { Registrados } \\
\text { (Litros) }\end{array} \\
2003 \text { a } \\
10 / 2005\end{array}$} & \multirow{2}{*}{$\begin{array}{c}\text { Não } \\
\text { Registrados }\end{array}$} \\
\hline & & $\begin{array}{c}\text { Falhas } \\
\text { Operac. }\end{array}$ & Manut. & Comunicação & $\begin{array}{l}\text { Transp. } \\
\text { Contrat. }\end{array}$ & Outro & & \\
\hline $\begin{array}{l}\text { Derrame } \\
\text { de asfaltos } \\
\text { diluídos }\end{array}$ & 22 & 5 & 1 & 2 & 9 & 5 & 226 & 15 \\
\hline $\begin{array}{l}\text { Derrame de } \\
\text { CAP 50/60 }\end{array}$ & 20 & 2 & 10 & 1 & 7 & 0 & 4665 & 11 \\
\hline $\begin{array}{l}\text { Derrame de } \\
\text { Petróleo Cru }\end{array}$ & 9 & 6 & 2 & 1 & 0 & 0 & 80 & 7 \\
\hline $\begin{array}{l}\text { Derrame de } \\
\text { MF (180 e } \\
380)\end{array}$ & 2 & 1 & 1 & 0 & 0 & 0 & 2100 & 0 \\
\hline TOTAL & 53 & 14 & 14 & 4 & 16 & 5 & 7071 & 33 \\
\hline
\end{tabular}

Quadro 4: Tipo e Quantidade de Ocorrência de Geração de Borra Oleosa, Causas Prováveis e Quantidade de Vazamentos Registrados e Não-Registrados.

Fonte: dados coletados na pesquisa de campo

Constatou-se que 39 das 53 ocorrências de geração de borra oleosa ocorreram em 2003, 7 em 2004 e 7 em 2005. Isso representa em termos percentuais que $73,58 \%$ dos eventos ocorreram em 2003, 13,2\% em 2004 e 13,2\% até outubro de 2005, conforme apresentado na Figura 1. Houve uma queda brusca do ano de 2003 para 2004 com relação ao número de ocorrências de geração de borra oleosa. Isso se deve principalmente a investimentos voltados para as questões de SMS (Segurança, Meio Ambiente e Saúde), manutenção de equipamentos e investimentos em novas tecnologias.

Do total de 53 RTA abertas, em 33 RTA não foi registrado nenhum quantitativo de produto derramado. Pode-se então inferir, que durante o período analisado, pode sido derramada uma quantidade maior de produtos. 


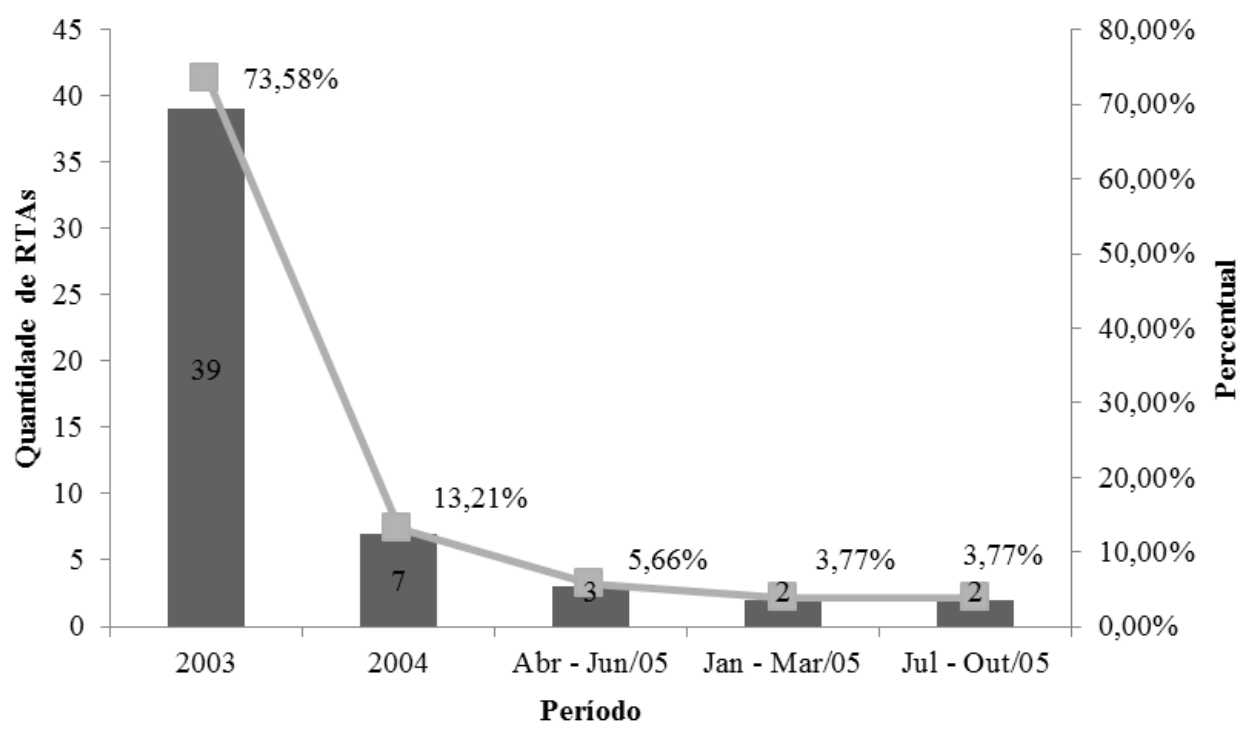

Figura 1: Número de ocorrências de geração de borra oleosa informadas nas RTAs.

Fonte: Dados coletados na pesquisa de campo

O gráfico de barras apresentado na Figura 2 permite priorizar as principais causas de ocorrências de geração de borra oleosa. O transporte contratado para o carregamento e descarregamento de produtos da PETROBRAS/ LUBNOR é o aspecto mais relevante no processo de geração do resíduo borra oleosa. Observa-se, que as falhas operacionais e de manutenção apresentam a mesma quantidade de registros nos Relatórios de Tratamento das Anomalias, seguido da comunicação.

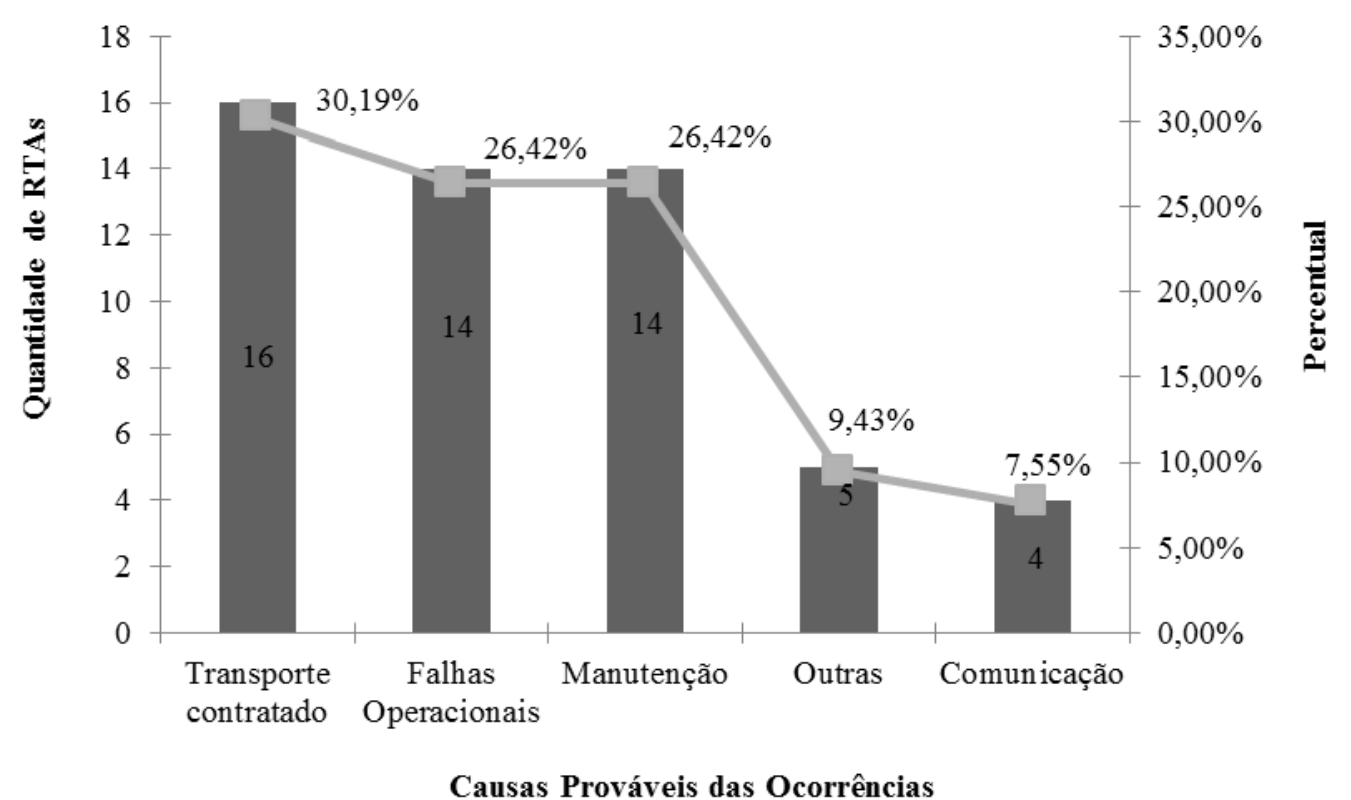

Figura 2: Quantidade de ocorrências de geração de borra oleosa e as suas causas mais prováveis

Fonte: Dados coletados na pesquisa de campo

As não-conformidades relacionadas com o transporte contratado são apresentadas na Figura 3 e envolvem, prioritariamente, a presença de emulsão ou água na carreta, seguida de carreta furada, problemas de soldagem e fenda na carreta. 


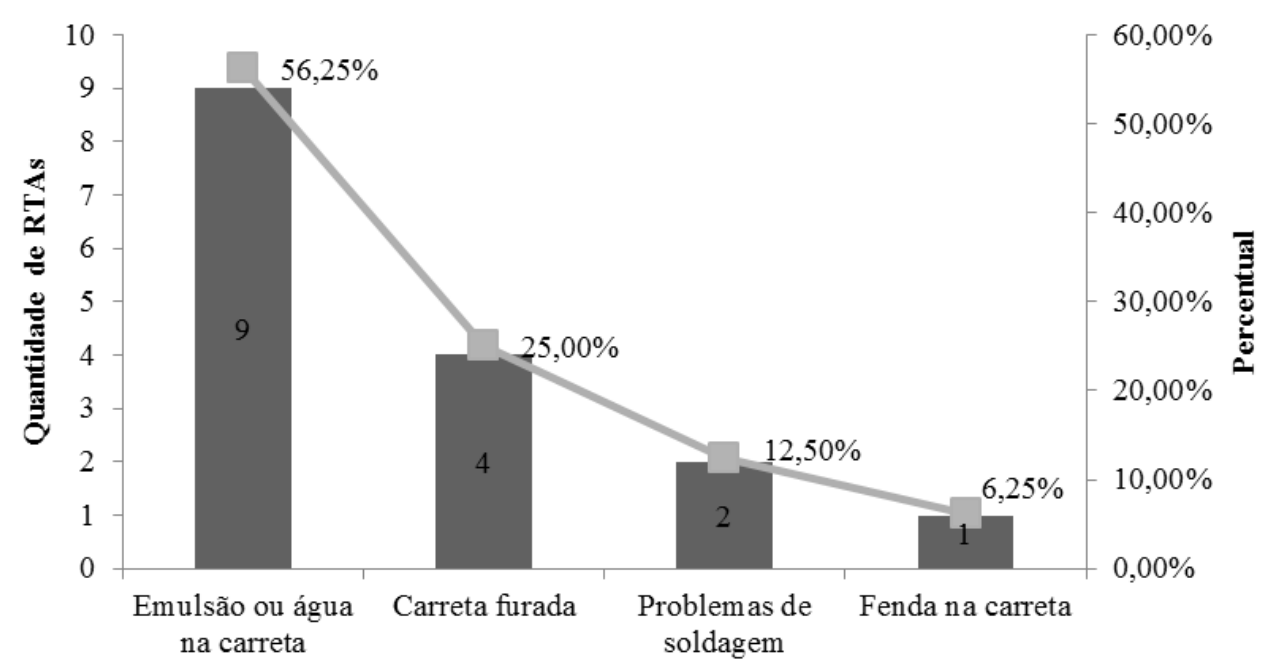

Tipos de problemas com o transporte contratado

Figura 3: Quantidade de ocorrências de geração de borra oleosa decorrentes de falhas com as empresas de transporte contratada

Fonte: Dados coletados na pesquisa de campo

Fazendo a análise quantitativa das principais falhas operacionais que influenciam no processo de geração de borra oleosa, observa-se na Figura 4, principalmente, a ocorrência de válvulas abertas, seguida de ponto de coleta para amostragem aberto, operador ausente na drenagem de tanque, abertura antecipada da boca de visita superior da carreta no momento do descarregamento na Estação de Carregamento Rodoviário (ECR). Em menor proporção observam-se parafusos folgados, ausência de cap (uma peça que atua como duplo bloqueio no mangote de descarga da carreta) e aperto insuficiente da mangueira na tubulação.

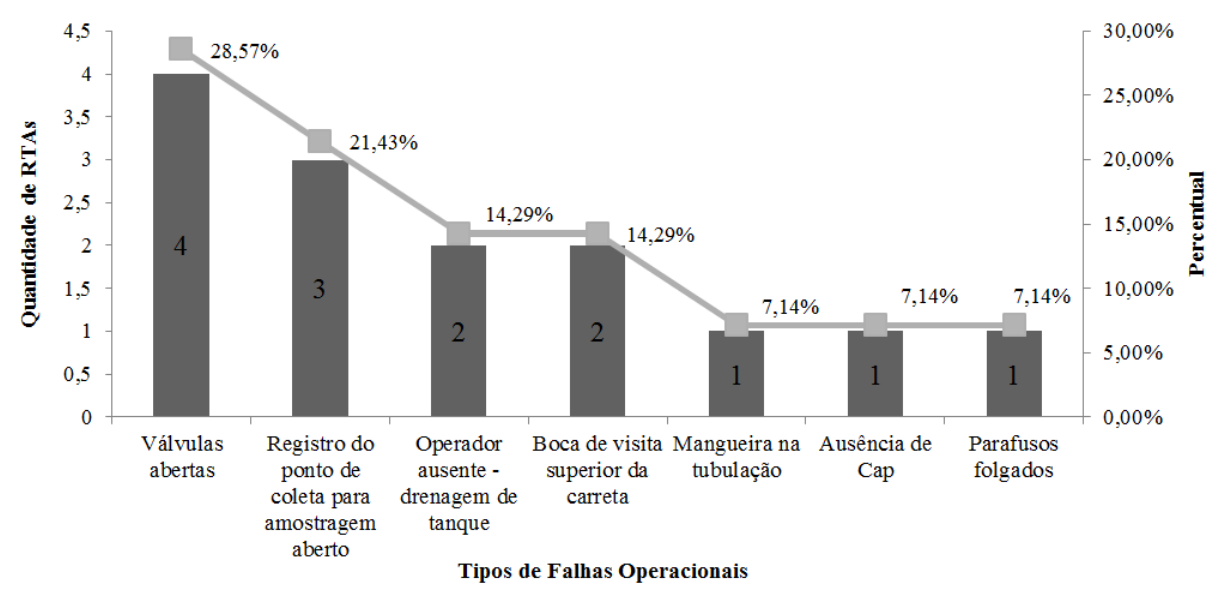

Figura 4: Quantidade de ocorrências de geração de borra oleosa decorrente de falhas operacionais

Fonte: Dados coletados na pesquisa de campo

Analisando os problemas com manutenção, observase na Figura 5, principalmente, a ocorrência de falhas em juntas e problemas com as gaxetas, seguida de manutenção em atraso, válvula desgastada, furo na linha de descarga e vazamento pelo costado do tanque. 


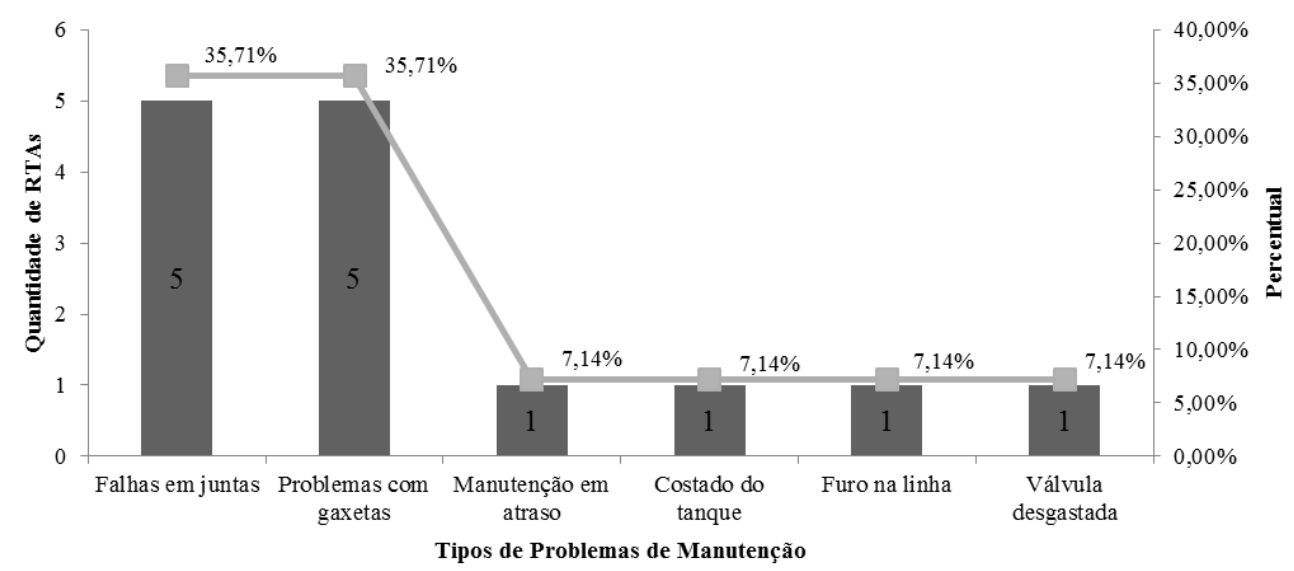

Figura 5: Quantidade de ocorrências de geração de borra oleosa decorrente de falhas de manutenção

Fonte: Dados coletados na pesquisa de campo

Para os problemas de comunicação verifica-se na Figura 6 que do total de casos registrados, 3 são por carregapor falhas de comunicação entre operadores da ECR e mento de produtos além da capacidade da carreta e 1 os motoristas das carretas.

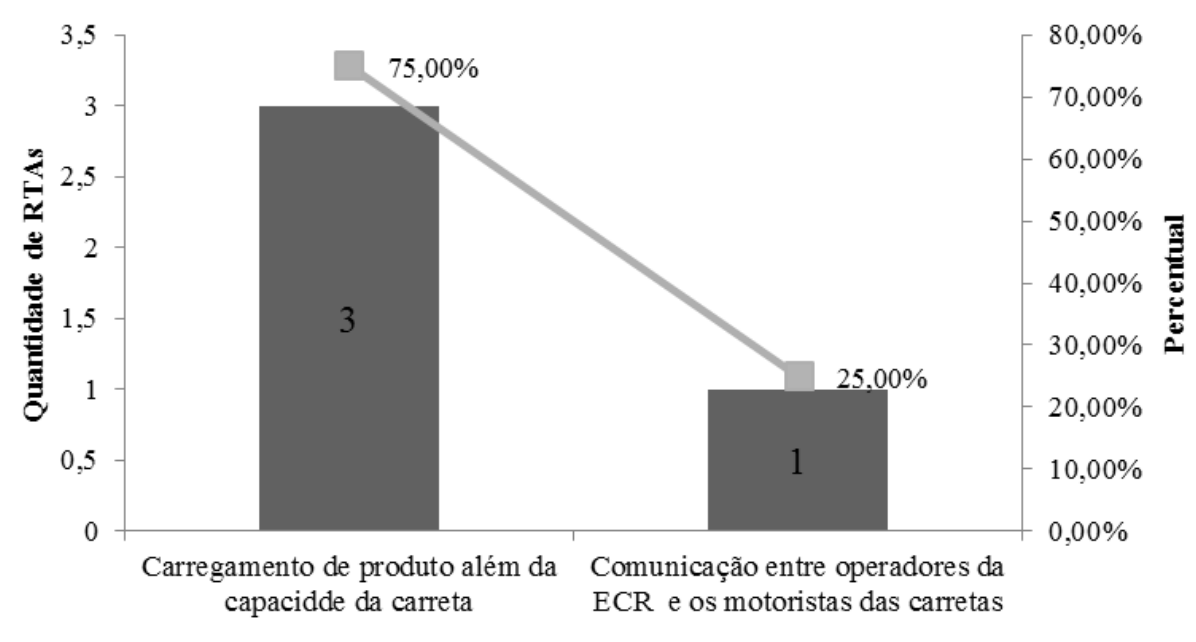

Tipos de problemas de comunicação

Figura 6: Quantidade de ocorrências de geração de borra oleosa decorrentes de problemas de comunicação

Fonte: Dados coletados na pesquisa de campo

Por fim, do total das causas prováveis de geração de borra oleosa, 5 foram caracterizadas como outras, pois nas RTAs não foram registradas nenhum tipo de causas.
Demonstrando a necessidade de conscientização dos operadores da importância do registro das anomalias para solução dos problemas de geração de resíduos. 


\section{Discussão}

\subsection{Bloqueio de Aspectos Ambientais e Ações Mitigadoras dos Impactos Ambientais da Borra Oleosa}

As propostas de melhorias no PGRS estão apresentadas no Quadro 5. Na etapa de coleta da borra oleosa após um derramamento, recomenda-se um treinamento intensivo dos procedimentos operacionais e de conscientização ambiental dos operadores quanto aos riscos de manuseio de um resíduo perigoso. A definição e delimitação da área atingida e a coleta somente do material derramado previne o aumento de volume do resíduo gerado. A descrição dos Equipamentos de Proteção Individuais (EPIs) utilizados na tarefa de coleta da borra oleosa evita acidentes de trabalho. Recomenda-se também o registro completo e detalhado da anomalia no documento pertinente, a RTA, além da ficha do resíduo.

\begin{tabular}{|c|c|c|c|}
\hline $\begin{array}{l}\text { TAREFA } \\
\text { DO PGRS }\end{array}$ & $\begin{array}{c}\text { ASPECTOS } \\
\text { AMBIENTAIS }\end{array}$ & $\begin{array}{c}\text { IMPACTOS } \\
\text { AMBIENTAIS }\end{array}$ & MEDIDAS MITIGADORAS \\
\hline $\begin{array}{l}\text { Coleta do resíduo } \\
\text { borra oleosa. }\end{array}$ & $\begin{array}{l}\text { Contaminação com } \\
\text { outros resíduos. } \\
\text { Aumento da área } \\
\text { contaminada. }\end{array}$ & $\begin{array}{l}\text { Aumento da contami- } \\
\text { nação ambiental. } \\
\text { Geração de mais resí- } \\
\text { duos. } \\
\text { Contaminação do ope- } \\
\text { rador. } \\
\text { Acidentes com lesões. }\end{array}$ & $\begin{array}{l}\text { Definir e delimitar a área atingida. } \\
\text { Coletar e acondicionar imediatamente os resí- } \\
\text { duos após a sua geração. } \\
\text { Coletar somente o material contaminado. } \\
\text { Fazer a coleta com cuidado e atenção. } \\
\text { Garantir a total remoção do material contami- } \\
\text { nado. } \\
\text { Isolar a área para evitar trânsito de pessoas / } \\
\text { veículos sobre os resíduos. } \\
\text { Estabelecer para cada classe de resíduos os } \\
\text { EPIs mínimos a serem utilizados. }\end{array}$ \\
\hline $\begin{array}{l}\text { Descontaminação } \\
\text { de materiais e/ou } \\
\text { ferramentas com } \\
\text { água quente, va- } \\
\text { por ou solventes. }\end{array}$ & $\begin{array}{l}\text { Derrame da água } \\
\text { residual da descon- } \\
\text { taminação. } \\
\text { Vazamento de sol- } \\
\text { ventes orgânicos. }\end{array}$ & $\begin{array}{l}\text { Contaminação ambien- } \\
\text { tal. } \\
\text { Contaminação do ope- } \\
\text { rador. } \\
\text { Queimaduras no ope- } \\
\text { rador. }\end{array}$ & $\begin{array}{l}\text { Adotar medidas preventivas contra vazamentos. } \\
\text { Fazer a descontaminação somente em local } \\
\text { adequado. } \\
\text { Coletar imediatamente a água derramada. } \\
\text { Descontaminar o local afetado. } \\
\text { Manter o programa de coleta seletiva. } \\
\text { Monitorar água da última lavagem para assegu- } \\
\text { rar a descontaminação. }\end{array}$ \\
\hline $\begin{array}{l}\text { Acondiciona- } \\
\text { mento do resíduo } \\
\text { borra oleosa. }\end{array}$ & $\begin{array}{l}\text { Derrames de resí- } \\
\text { duos. } \\
\text { Vazamentos de } \\
\text { resíduos nos tam- } \\
\text { bores. }\end{array}$ & $\begin{array}{l}\text { Contaminação ambien- } \\
\text { tal. } \\
\text { Contaminação do ope- } \\
\text { rador. } \\
\text { Aumento da geração de } \\
\text { resíduos. }\end{array}$ & $\begin{array}{l}\text { Inspecionar antecipadamente os tambores. } \\
\text { Coletar imediatamente o resíduo derramado. } \\
\text { Adotar medidas preventivas e de controle, du- } \\
\text { rante a tarefa. } \\
\text { Fazer o acondicionamento dos resíduos somen- } \\
\text { te em área pavimentada e coberta. }\end{array}$ \\
\hline $\begin{array}{l}\text { Armazenamento } \\
\text { temporário do } \\
\text { resíduo borra } \\
\text { oleosa. }\end{array}$ & $\begin{array}{l}\text { Derrames de resí- } \\
\text { duos. } \\
\text { Vazamentos de } \\
\text { resíduos nos tam- } \\
\text { bores. } \\
\text { Mistura com outros } \\
\text { resíduos. }\end{array}$ & $\begin{array}{l}\text { Contaminação ambien- } \\
\text { tal. } \\
\text { Contaminação do ope- } \\
\text { rador. } \\
\text { Contaminação de ou- } \\
\text { tros resíduos não pe- } \\
\text { rigosos, gerando mais } \\
\text { resíduos classe I. }\end{array}$ & $\begin{array}{l}\text { Isolar e impermeabilizar a área afetada. } \\
\text { Remover o mais breve possível o resíduo arma- } \\
\text { zenado temporariamente para destinação final. } \\
\text { Fazer a descontaminação do local. } \\
\text { Inspecionar periodicamente o local de estoca- } \\
\text { gem quanto a impermeabilização e liberação de } \\
\text { chorume. } \\
\text { Adotar medidas preventivas e de controle. } \\
\text { Adotar medidas de controle do estoque. }\end{array}$ \\
\hline $\begin{array}{l}\text { Disposição final } \\
\text { do resíduo borra } \\
\text { oleosa. }\end{array}$ & $\begin{array}{l}\text { Disposição em } \\
\text { local não progra- } \\
\text { mado. } \\
\text { Derrames de resí- } \\
\text { duos. } \\
\text { Vazamentos de } \\
\text { resíduos nos tam- } \\
\text { bores. }\end{array}$ & $\begin{array}{l}\text { Contaminação ambien- } \\
\text { tal. } \\
\text { Contaminação do ope- } \\
\text { rador. }\end{array}$ & $\begin{array}{l}\text { Planejar antecipadamente a disposição final, } \\
\text { com visita ao local/empresa de disposição final. } \\
\text { Coletar imediatamente o resíduo derramado. } \\
\text { Inspecionar o local e adotar medidas preven- } \\
\text { tivas e corretivas. } \\
\text { Garantir a emissão do certificado de disposição } \\
\text { final. }\end{array}$ \\
\hline
\end{tabular}

Quadro 5. Aspectos e impactos ambientais para cada tarefa descrita no PGRS e sugestões de medidas mitigadoras para a geração de borra oleosa 
Na descontaminação de materiais e/ou ferramentas com água quente recomenda-se também uma conscientização ambiental dos operadores. Principalmente, quanto ao uso racional da água utilizada para essa descontaminação, prevenindo a geração excessiva de efluentes, a utilização da água tratada e diminuindo o consumo de energia da Unidade de Tratamento de Efluentes.

Para a etapa de acondicionamento, propõe-se a identificação correta do resíduo borra oleosa, por meio de uma ficha de identificação, devendo ter todos os campos preenchidos, facilitando o rastreamento das etapas de sua geração. Na Central de Resíduos, o armazenamento temporário, deve ocorrer mediante o preenchimento completo da ficha de entrada do resíduo borra oleosa. Obtendo dessa forma um controle mais eficiente de todas as etapas de sua geração. E na etapa de disposição final, recomenda-se um estudo da viabilidade econômica e ambiental das opções de destinação da borra oleosa.

Adicionalmente, propõe-se uma reavaliação dos procedimentos operacionais quanto a previsão de instruções que evitem falhas operacionais. Recomenda-se também exigir das empresas contratadas uma melhor inspeção dos veículos para o carregamento de produto. Com relação à manutenção, propõe-se uma avaliação da manutenção preventiva dos equipamentos e dos materiais. E por fim, treinar os operadores da Estação de Carregamento Rodoviário quanto à importância da boa comunicação entre os parceiros durante as operações e do trabalho em equipe.

\section{2 Recomendações para uma Melhor Gestão Ambiental da Borra Oleosa}

Com base nos dados coletados e na análise dos procedimentos operacionais de armazenamento e movimentação de resíduos, carregamento e descarregamento rodoviário, amostragem de produtos e drenagem de tanques foram definidas algumas recomendações com o objetivo de melhorar a operacionalização do PGRS, focando na minimização e no controle da geração de borra oleosa. O Quadro 6 mostra as recomendações para cada falha com o transporte contratado. Observa-se nos procedimentos de carregamento rodoviário não é exigido ao fornecedor uma carreta em perfeitas condições de carregamento, ou seja, sem trincas, furos, problemas de soldagem de carretas e fendas.

\begin{tabular}{|c|c|c|}
\hline TIPO DE FALHA & FALHAS DETECTADAS & RECOMENDAÇÕES \\
\hline \multirow{4}{*}{$\begin{array}{l}\text { Transporte } \\
\text { Contratado }\end{array}$} & Carreta chega furada & $\begin{array}{l}\text { 1. Prever nos procedimentos de carregamento que as } \\
\text { carretas devem estar em condições perfeitas para o carre- } \\
\text { gamento; } \\
\text { 2. Inspecionar a carreta antecipadamente enquanto a mes- } \\
\text { ma encontra-se esperando o carregamento; } \\
\text { 3. Conscientização ambiental dos operadores próprios e } \\
\text { das empresas contratadas. }\end{array}$ \\
\hline & Emulsão na carreta & $\begin{array}{l}\text { 1. Treinamento mais adequado dos procedimentos opera- } \\
\text { cionais; } \\
\text { 2. Inspecionar a carreta antecipadamente enquanto a mes- } \\
\text { ma encontra-se esperando o carregamento; } \\
\text { 3. Conscientização ambiental dos operadores próprios e } \\
\text { das empresas contratadas. }\end{array}$ \\
\hline & $\begin{array}{l}\text { Problemas de soldagem } \\
\text { na carreta }\end{array}$ & $\begin{array}{l}\text { 1. Prever nos procedimentos de carregamento que as } \\
\text { carretas devem estar em condições perfeitas para o carre- } \\
\text { gamento; } \\
\text { 2. Inspecionar a carreta antecipadamente enquanto a mes- } \\
\text { ma encontra-se esperando o carregamento; } \\
\text { 3. Conscientização ambiental dos operadores próprios e } \\
\text { das empresas contratadas. }\end{array}$ \\
\hline & Fenda na carreta & $\begin{array}{l}\text { 1. Prever nos procedimentos de carregamento que as } \\
\text { carretas devem estar em condições perfeitas para o carre- } \\
\text { gamento; } \\
\text { 2. Inspecionar a carreta antecipadamente enquanto a mes- } \\
\text { ma encontra-se esperando o carregamento; } \\
\text { 3. Conscientização ambiental dos operadores próprios e } \\
\text { das empresas contratadas. }\end{array}$ \\
\hline
\end{tabular}

Quadro 6: Recomendações para as reduzir as falhas de transporte contratado levando a minimização e ao controle da geração de borra oleosa 
Entretanto, este mesmo procedimento prevê que o operador deve indagar ao motorista qual a última carga transportada pela carreta e caso tenha sido emulsão, não efetuar o carregamento, pois há risco do produto ferver e derramar. Contudo, mesmo que o motorista afirme que não carregou emulsão, o operador deve realizar uma inspeção visual da carreta, para verificar a ocorrência de vestígios d'água proveniente de outras fontes como chuva, por exemplo. Além da inspeção, recomenda-se reforçar o programa de conscientização ambiental dos operadores próprios e das empresas contratadas.

Observa-se que as possíveis falhas operacionais já estão previstas nos procedimentos. Dessa forma, recomenda-se reforçar o programa de treinamento e conscientização. Por exemplo, no caso das válvulas abertas, o procedimento de carregamento rodoviário de CAP 50/60 já determina que o motorista verifique se as tomadas de entrada, saída e drenos da carreta estão fechados e capeados. O procedimento de drenagem de tanques de petróleo e derivados determina que o operador permaneça junto aos drenos durante toda a operação de drenagem, para certificar-se, que as canaletas de drenagem no dique estejam desobstruídas e bloquear a válvula do dreno quando não houver mais água livre.

Por outro lado, em alguns casos, é necessário rever os procedimentos operacionais (Quadro 7). No caso da falha de abertura do registro do ponto de coleta de amostragem, observa-se que o procedimento de plano de amostragem não obriga o fechamento do registro do ponto de coleta de amostragem, após a coleta da amostra. O mesmo acontece no procedimento de descarga contingencial de carretas com petróleo para o tanque F-201E, onde não é previsto o momento ideal para abertura da boca de visita superior da carreta.

\begin{tabular}{|c|c|c|}
\hline TIPO DE FALHA & FALHAS DETECTADAS & RECOMENDAÇÕES \\
\hline \multirow{7}{*}{ Falhas Operacionais } & Válvulas das carretas abertas & $\begin{array}{l}\text { 1.Treinamento mais adequado dos procedimentos } \\
\text { operacionais; } \\
\text { 2. Inspecionar antecipadamente as carretas no esta- } \\
\text { cionamento ao lado do portão B da Lubnor enquanto } \\
\text { esperam pelo carregamento; } \\
\text { 3. Conscientização ambiental dos operadores. }\end{array}$ \\
\hline & $\begin{array}{l}\text { Registro do ponto de coleta } \\
\text { de amostragem aberto }\end{array}$ & $\begin{array}{l}\text { 1.Prever no procedimento o fechamento do registro } \\
\text { do ponto de coleta de amostragem, após a coleta da } \\
\text { amostra; } \\
\text { 2.Treinamento mais adequado dos procedimentos } \\
\text { operacionais; } \\
\text { 3. Conscientização ambiental dos operadores. }\end{array}$ \\
\hline & $\begin{array}{l}\text { Operador ausente na drenagem } \\
\text { de tanque }\end{array}$ & $\begin{array}{l}\text { 1.Treinamento mais adequado dos procedimentos } \\
\text { operacionais; } \\
\text { 2. Conscientização ambiental dos operadores. }\end{array}$ \\
\hline & $\begin{array}{l}\text { Abertura antecipada da Boca de vi- } \\
\text { sita superior da carreta no momento } \\
\text { do descarregamento de petróleo cru } \\
\text { na ECR }\end{array}$ & $\begin{array}{l}\text { 1. Prever no procedimento o momento ideal para } \\
\text { abertura da Boca de visita superior da carreta; } \\
\text { 2.Treinamento mais adequado dos procedimentos } \\
\text { operacionais; } \\
\text { 3.Conscientização ambiental dos operadores. }\end{array}$ \\
\hline & $\begin{array}{l}\text { Aperto insuficiente da mangueira } \\
\text { na tubulação }\end{array}$ & $\begin{array}{l}\text { 1. Treinamento operacional; } \\
\text { 2. Conscientização ambiental dos operadores. }\end{array}$ \\
\hline & $\begin{array}{l}\text { Ausência de cap (peça que atua como } \\
\text { duplo bloqueio no mangote de des- } \\
\text { carga da carreta) }\end{array}$ & $\begin{array}{l}\text { 1.Treinamento mais adequado dos procedimentos } \\
\text { operacionais; } \\
\text { 2.Inspeção antecipada das carretas no estacionamento } \\
\text { ao lado do portão B da Lubnor enquanto esperam pelo } \\
\text { carregamento; } \\
\text { 3. Conscientização ambiental dos operadores. }\end{array}$ \\
\hline & Parafusos folgados & $\begin{array}{l}\text { 1.Treinamento mais adequado dos procedimentos } \\
\text { operacionais; } \\
\text { 2.Inspeção antecipada das carretas no estacionamento } \\
\text { ao lado do portão B da Lubnor enquanto esperam pelo } \\
\text { carregamento. } \\
\text { 3. Conscientização ambiental dos operadores. }\end{array}$ \\
\hline
\end{tabular}

Quadro 7: Recomendações para reduzir as falhas operacionais que resultam na geração de borra oleosa 
No caso da manutenção foram detectadas falhas em juntas, problemas com as gaxetas das bombas, manutenção de tanques em atrasado, vazamento pelo costado do tanque, furo em linha de descarga e válvula desgastada. Apesar do eficiente programa de manutenção e expansão sugere-se melhorar o atendimento ao cronograma planejado de inspeção externa e interna dos tanques de armazenamento de petróleo e derivados, das linhas de descarga de produtos e das válvulas de equipamentos.
Observam-se falhas de comunicação entre operadores da Estação de Carregamento Rodoviário (ECR) e os motoristas das carretas, o que implica em carregamento de produtos além da capacidade da carreta. De forma semelhante, deve ser reforçado o treinamento dos operadores da ECR quanto à importância da boa comunicação entre os parceiros durante as operações e do trabalho em equipe e a conscientização ambiental dos operadores. O quadro 8 mostra recomendações para cada falha de comunicação detectada.

\begin{tabular}{|l|l|l|}
\hline TIPO DE FALHA & FALHAS DETECTADAS & RECOMENDAÇÕES \\
\hline \multirow{5}{*}{ Comunicação } & $\begin{array}{l}\text { Carregamento de produtos além } \\
\text { da capacidade da carreta }\end{array}$ & $\begin{array}{l}\text { 1. Treinar os operadores da ECR quanto à importância } \\
\text { da boa comunicação entre os parceiros durante as ope- } \\
\text { rações e do trabalho em equipe; } \\
\text { 2. Conscientização ambiental dos operadores. }\end{array}$ \\
\cline { 2 - 3 } & $\begin{array}{l}\text { Comunicação entre operadores } \\
\text { da ECR e os motoristas das car- } \\
\text { retas }\end{array}$ & $\begin{array}{l}\text { 1. Treinar os operadores da ECR quanto à importância } \\
\text { da boa comunicação entre os parceiros durante as ope- } \\
\text { rações e do trabalho em equipe; } \\
\text { 2. Conscientização ambiental dos operadores. }\end{array}$ \\
\hline
\end{tabular}

Quadro 8: Recomendações para reduzir as falhas de comunicação e minimizar a geração de borra oleosa.

Fonte: Elaborado a partir dos dados coletados na pesquisa de campo

Faz-se também recomendações julgadas necessárias para outros tipos de falhas detectadas ao longo desse diagnóstico, objetivando assim uma otimização no controle de geração do resíduo borra oleosa e rastreamento de todo processo de geração, desde a ocorrência a identificação do resíduo no local de armazenagem, conforme apresentado no Quadro 9.

\begin{tabular}{|c|c|c|}
\hline TIPO DE FALHA & FALHAS DETECTADAS & RECOMENDAÇÕES \\
\hline \multirow{4}{*}{ Formulários } & $\begin{array}{l}\text { Preenchimento incompleto } \\
\text { das RTAs }\end{array}$ & $\begin{array}{l}\text { 1. Preencher todos os campos de informações existentes } \\
\text { nas RTAs. }\end{array}$ \\
\hline & $\begin{array}{l}\text { Falhas no controle de entrada } \\
\text { de resíduos na Central (ficha de } \\
\text { entrada) }\end{array}$ & $\begin{array}{l}\text { 1. Elaborar uma ficha de entrada de resíduos mais deta- } \\
\text { lhada, com informações mais específicas; } \\
\text { 2. Treinar os operadores responsáveis e exigir o preen- } \\
\text { chimento completo da ficha. }\end{array}$ \\
\hline & $\begin{array}{l}\text { Ficha de identificação } \\
\text { do resíduo na Central }\end{array}$ & $\begin{array}{l}\text { 1. Elaborar uma ficha de identificação dos resíduos mais } \\
\text { detalhada, com informações mais específicas; } \\
\text { 2. Treinar os operadores responsáveis e exigir o preen- } \\
\text { chimento completo da ficha. }\end{array}$ \\
\hline & $\begin{array}{l}\text { Ficha de movimentação interna } \\
\text { de resíduos }\end{array}$ & $\begin{array}{l}\text { 1. Elaborar uma ficha de movimentação interna dos } \\
\text { resíduos mais detalhada, com informações mais espe- } \\
\text { cíficas; } \\
\text { 2. Treinar os operadores responsáveis e exigir o preen- } \\
\text { chimento completo da ficha. } \\
\text { 3. Gerência responsável pela geração do resíduo deve } \\
\text { arquive essa ficha após a entrega do mesmo na Central } \\
\text { de Resíduos. }\end{array}$ \\
\hline
\end{tabular}

Quadro 9: Recomendações para reduzir as falhas detectadas no preenchimento dos formulários que podem resultar na geração de borra oleosa 
Recomenda-se um reforço no treinamento do tratamento das não conformidades, mostrando a importância no preenchimento de todos os dados para posterior tratamento. $\mathrm{O}$ diagnóstico mostrou também a necessidade de melhorar a identificação dos resíduos armazenados temporariamente na Central de Resíduos. A identificação deve ser ampliada para a movimentação da borra oleosa das áreas produtoras para a Central de Resíduos. Para tanto, sugere-se a elaboração de uma ficha mais detalhada de entrada, armazenamento e movimentação interna dos resíduos, e a gerência responsável pela geração do resíduo deve arquivar uma cópia dessa ficha, melhorando o controle interno.

\section{Conclusão}

A busca de soluções para a geração, armazenamento e disposição final responsável da borra oleosa passa por um diagnóstico e identificação de oportunidades de melhorias, que objetivam contribuir para a otimização do plano de gerenciamento de resíduos sólidos (PGRS). O trabalho partiu de uma caracterização de todo o processo de geração de resíduos, priorizando a geração de borra oleosa, em função do impacto ambiental, do volume gerado e da quantidade crescente armazenada na Central de Resíduos. A borra oleosa não é apenas resultado do processo de produção de combustíveis e derivados, mas de todos os processos que operacionalizam o sistema produtivo, ou seja, na estocagem de matéria-prima, na estocagem e expedição de produtos, na manutenção de equipamentos, tanques e materiais, limpeza de tubovias e canaletas de águas oleosas.

A minimização da geração de borra oleosa requer o aprimoramento de técnicas, instrumentos e métodos operacionais, principalmente, aqueles relacionados com o transporte contratado. Observa-se uma maior porcentagem de ocorrências de geração de borra oleosa, devendo-se, então, elaborar treinamentos mais eficazes e aprofundados com os operadores da ECR (Estação de Carregamento Rodoviário) e exigir aos fornecedores de carretas uma melhor inspeção dos veículos, antes que cheguem às instalações da PETROBRAS/LUBNOR para carregamento de derivados de petróleo.

Este fato merece extrema importância, visto que, no momento de um derramamento de produto por problemas com carretas, a PETROBRAS/LUBNOR cobra ao fornecedor todos os custos embutidos naquela ocorrência. Porém, permanece com o passivo ambiental e com a responsabilidade de gerenciar todas as etapas necessárias até a destinação adequada, o que é necessário para se adequar à legislação vigente.

Outro aspecto importante do estudo foi a necessidade de melhorar as operações de controle da geração do resíduo borra oleosa em termos de registro de ocorrências geradoras e preenchimento completo e adequado dos documentos pertinentes, como RTAs (Registro e Tratamento de Anomalias) e fichas de resíduos. Esse controle proporciona um rastreamento eficaz de todas as etapas do processo de geração de borra oleosa. Através das RTAs é possível identificar onde a borra oleosa foi gerada; qual a gerência que gerou; qual o motivo da geração e a quantidade de resíduo gerado. Com base nestas informações é possível propor melhorias de processo.

A pesquisa revelou também uma significativa evolução na gestão interna dos resíduos ao longo dos anos na PETROBRAS/LUBNOR através da contínua revisão e aperfeiçoamento dos padrões e dos procedimentos operacionais, aliado ao treinamento das equipes envolvidas. Observa-se, finalmente, que a continuidade desse estudo com a linha de raciocínio exposta nesse trabalho permitiu a sistematização de métodos e suas utilizações em ações voltadas para otimização da gestão ambiental de resíduos sólidos da PETROBRAS/LUBNOR, reduzindo também os custos e otimizando o tempo de armazenamento temporário na Central de Resíduos.

Uma melhoria do sistema integrado de gestão da qualidade, meio ambiente, saúde e segurança operacional requer uma atuação em todos os processos produtivos, de manutenção e de transferência e estocagem, com a melhoria dos procedimentos operacionais que envolvem a PETROBRAS/LUBNOR e as empresas contratadas, além de um contínuo programa de treinamento e conscientização ambiental dos empregados próprios e contratados.

\section{Agradecimentos}

Ao Conselho Nacional de Desenvolvimento Científico e Tecnológico (CNPq) e a Agência Nacional do Petróleo, Gás Natural e Biocombustíveis (ANP) pelo apoio financeiro ao projeto de pesquisa.

A PETROBRAS/LUBNOR pelo apoio ao desenvolvimento do projeto de pesquisa e a disponibilidade das informações.

\section{Referências}

ABREU, M. C. S.; SOUSA, H. F. Plano de Gerenciamento de Resíduos Sólidos na Indústria de Petróleo: O Caso PETROBRAS/Fazenda Belém. Anais do XXV Encontro Nacional de Engenharia de Produção. Porto Alegre, 2005.

Associação Brasileira de Normas Técnicas (ABNT). NBR 10004: Resíduos Sólidos - Classificação. Rio de Janeiro, maio 2004. 
NBR 8418: Apresentação de Projetos de Aterros de Resíduos Industriais Perigosos. Rio de Janeiro, dezembro 1983.

NBR 7500: Identificação para o Transporte Terrestre, Manuseio, Movimentação e Armazenamento de Produtos. Rio de Janeiro, dez. 1983.

CASTORENA-CORTÉS, G.; ROLDÁN-CARRILLO, T.; ZAPATA-PEÑASCO, I.; REYES-AVILA, J.; QUEJAKÉ, L.; MARÍN-CRUZ, J.; OLGUÍN-LORA, P. Microcosm Assaysand Taguchi Experimental Design for Treatment of Oil Sludge Containing High Concentration of Hydrocarbons. Bioresource Technology, 100, p, 5671-5677, 2009

Centro Nacional de Tecnologias Limpas (CNTL). Manual: Questões ambientais e produção mais limpa. Curso de Formação de Consultores em Produção mais Limpa, Fortaleza, dez. 2001.

Manual metodologia de implantação do programa de produção mais limpa. Curso de Formação de Consultores em Produção mais Limpa, Fortaleza, jan. 2002.

CETESB - Companhia de Tecnologia de Saneamento Ambiental. Resíduos Sólidos Industriais. São Paulo. 2 ed. rev. ampl, 1993.

FÉDÉRATION DES EXPERTS COMPTABLES EUREPÉENS (FEE). Review of international accounting standards for environmental issues. 3. ed. FEE, 1999.

KARAMALIDIS, A. K.; VOUDRIAS, E. A. CementBased Stabilization/Solidification Of Oil Refinery Sludge:Leaching Behavior of Alkanes and PAHS. Journal of Hazardous Materials, 148, p. 122-135, 2007.

MCCARTHY, K.; WALKER, L.; VIGOREN, L.; BARTEL, J. Remediation of Spilled Petroleum Hydrocarbons by in Situ Landfarmingat an Arctic Site.Estados Unidos, 2004. ELSEVIER, Science Direct. Acesso em: jan. 2005. Disponível em: <www.sciencedirect.com>.

ROJAS, J. W. J.; CONSOLI, N. C.; HEINECK, K. S. Análises do Comportamento Físico de um Solo Contaminado por Borra Oleosa Ácida e Encapsulado com Cimento Portland. Eng. Sanit. Ambient. v. 13, n. 2, abr./ jun., p. 217-225, 2008

ROLDÁN-CARRILLO, T.; CASTORENA-CORTÉS, G.; ZAPATA-PEÑASCO, I.; REYES-AVILA J.; OLGUÍN-LORA, P. Aerobic Biodegradation of Sludge with High Hydrocarbon Content Generated by a Mexican Natural Gas Processing Facility, Journal of Environmental Management, v. 95, p. 593-598, 2012

SARKIS, J.; RASHEED, A. Greening the Manufacturing Function. Business Horizons Revue, Sept./Oct. 1995.

SOARES, J. C. C. Modelagem de Sistemas de Informações para o Gerenciamento Integrado de Cadeias Logísticas: uma Demonstração das Possibilidades de Aplicação na Indústria de Petróleo. Dissertação de Mestrado PPGEP/UFSC, Florianópolis, Brasil, 2000.

TREZZA, M. A.; SCIAN, A. N. Waste Fuels: Their Effect on Portland Cement Clinker. Argentina, 2004. ELSEVIER, Science Direct. Acesso em: jan. 2005. Disponível em: <www.sciencedirect.com $>$.

TRINDADE, P. V. O.; SOBRAL, L. G.; RIZZO, A. C. L.; LEITE, S. G. F.; SORIANO, A. U. Bioremediation of a weathered and a recently oil-contaminated soils from Brazil: a comparison study. Rio de Janeiro, 2005. ELSEVIER, Science Direct. Acesso em: jan. 2005.

VALLE, C. E. do. Como se Preparar para as Normas ISO 14000: Qualidade Ambiental: O Desafio de ser Competitivo Protegendo o Meio Ambiente. São Paulo: Pioneira: 2000.

VAN OUDENHOVEN, J.A.C.M., COOPER, G.R., CRICCHI, G., GINESTE, J., PÖTZL, R., MARTIN, D.E. Oil refinery waste, disposal methods and costs 1993 survey. CONCAWE, Brussels Report 1/95, p. 1-39, 1995.

XU, N.; WANG, W. X.; HAN, P. F.; LU, X. P. Effects of Ultrasound on Oily Sludge Deoiling. Journal of. Hazardous Materials, v. 171, p. 914-917, 2009.

ZHANG, J.; LI, J.; THRING, R.W.; SONG, X. Oil Recovery from Refinery Oily Sludge via Ultrasound and Freeze/thaw. Journal of Hazardous Material, p. 203-204, p. 195-203, 2012.

Recebido em 06/10/2009. Aceito em 07/08/2012. 